
Bartın Üniversitesi
Eğitim Fakültesi Dergisi
Cilt 6, Sayı 1, s. 1-15, Şubat 2017
BARTIN - TÜRKIYE

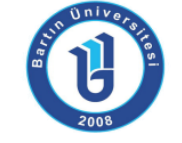
Bartin University
Journal of Faculty of Education
ISSN: 1308-7177

\title{
2013 Yılı Fen Bilimleri Öğretim Programı Kazanımlarının Yenilenmiş Bloom Taksonomisine Göre Analizi ve Değerlendirilmesi
}

Seraceddin Levent ZORLUOĞLU, Arş.Gör. Dr., Artvin Çoruh Üniversitesi Eğitim Fakültesi, leventzorluoglu@artvin.edu.tr Ayşe ŞAHINTÜRK; Arş. Gör, Artvin Çoruh Üniversitesi Eğitim Fakültesi, shntrk@hotmail.com

Kübra Elif BAĞRIYANIK; Arş. Gör, Artvin Çoruh Üniversitesi Eğitim Fakültesi, ekbagriyanik@artvin.edu.tr

Öz: Çalışmada, 2013 yılı Fen Bilimleri Öğretim Programı kazanımlarının yenilenmiş Bloom taksonomisine göre hangi düzeyde olduğu ve nasıl bir eğilim gösterdiğini ortaya koymak amaçlanmıştır. Bu amaçla Fen Bilimleri Öğretim Programı kazanımlarının yenilenmiş Bloom taksonomisine göre incelenmiş ve sınıflanması yapılmıştır.

Çalışma doküman incelemesi yöntemi kullanılarak gerçekleştirilmiştir. 2013 yılında yayınlanan Fen Bilimleri Dersi Öğretim Programı kazanımlarının yenilenmiş Bloom taksonomisine göre nasıl bir eğilim gösterdiğini ortaya koymak amacıyla yenilenmiş Bloom taksonomisine göre analizi yapılmıştır. Bu amaçla Fen Bilimleri Dersi Öğretim programında yer alan 330 kazanım incelenmiştir. Verilerin analizinde güvenirlik hesaplaması yapılmış ve güvenirlik katsayısı .88 bulunduğundan analizin güvenilir olduğu düşünülmüştür. Analiz bulgularına göre bilgi boyutunda: en çok kavramsal bilgi düzeyinde kazanıma yer verildiği, en az ise üstbilişsel bilgi düzeyinde kazanıma yer verildiği; bilişsel süreç boyutunda: en çok anlama düzeyinde kazanıma, en az ise değerlendirme düzeyinde kazanıma yer verildiği belirlenmiştir. Fen Bilimleri Öğretim Programı kazanımlarında üst düzey bilişsel süreç boyutlara yeteri kadar yer verilmediği ortaya çıkmıştır. Ayrıca bilgi boyutu basamaklarında kazanımların homojen dağılım göstermediği ve öğrenci öğrenmelerini aktif kılıcı üst düzey bilgi boyutuyla ilgi kazanımlara ağırlık verilmediği sonucu çıkmıştır.

Anahtar Kelimeler: Fen Öğretim Programı, Kazanımlar, Program Değerlendirme, Yenilenmiş Bloom Taksonomisi.

\section{Analysis and Evaluation of Science Course Curriculum Learning Outcomes of the Year 2013 According to the Revised Bloom Taxonomy}

\begin{abstract}
In this study, it is aimed to find out the learning outcome in science course curriculum that was started to applied in 2013, being at which level and how its tendency according to revised bloom taxonomy. For this purpose, the learning outcome in science course curriculum have been examined and classified on the basis of Revised Bloom Taxonomy.

The study has been conducted using the method of document analysis. The learning outcome of science course curriculum that have been analyzed according to revised Bloom Taxonomy with the aim of finding out the tendency of the learning outcome to the revised Bloom Taxonomy. For this purpose, the 330 learning outcome placing in the science course program have been examined. The Reliability computing has been made in the analysis of data and because the reliability co-efficient .88 it is considered that the analysis is reliable. According to the analysis results it has been defined that in knowledge dimension: the most learning outcome are given in the conceptual knowledge, the least learning outcomes are given in the metacognitive knowledge; in Cognitive processes dimension the most learning outcome are given at the level of understanding, the least learning outcome are given at the level of the evaluation. It has been found out that the senior cognitive process dimensions have not been taking place adequately in the learning outcome of science course curriculum. Furthermore, it has been induced that there has not been a homogenous distribution of the learning outcome at the cognitive dimension step and there has not been a focus on the learning outcome that are related to the senior cognitive dimension, activating e learnings of students.
\end{abstract}

Key Words: Science Course Curriculum, Learning Outcome, Program Evaluation, Revised Bloom Taxonomy. 


\section{GíRiş}

Fen eğitimi, fen öğretim programında yer alan kazanımların öğrenciler tarafından tecrübe edinerek öğrenmelerini; öğrenci tarafından kazanılması gereken tutum ve becerileri, yetenekleri doğrultusunda kazandırmayı amaçlamaktadır (Çepni, 2006; Uslu ve Akgün, 2016). Bu sayede araştıran, sorgulayan, etkili kararlar veren, problem çözen, kendisine güvenen, işbirlikçi ortama dâhil olan, etkili iletişim kuran ve fen öğrenen bireyler yetişmektedir (MEB, 2006).

Eğitim programı, bir eğitim kurumunda milli eğitimin ve kurumun amaçlarının gerçekleşmesi için öğrenene yönelik tüm faaliyetleri kapsar (Demirel, 2011; Küçükahmet, 2009). Eğitim programında bu faaliyetler gerçekleştirilirken hedef- içerik- öğrenme/öğretmen süreci- değerlendirme öğeleri göz önüne alınır. Bu noktada eğitim kasıtlı bir kültürlenme olduğundan eğitim programlarının planlı olması kaçınılmazdır. Böylece öğrenme yaşantıları da eğitim programının en önemli boyutu konumuna gelmektedir (Demirel, 2011). Dolayısıyla öğrenmenin planlı, programlı ve verimli bir şekilde yürütülebilmesi adına eğitim programı içerisinde yer alan öğretim programlarına ihtiyaç duyulmaktadır.

Öğretim programı, bir dersin öğretme-öğrenme süreçleri ile ilgili tüm etkinliklerinin, bireye okulda ya da okul dışında kazandırılması amacıyla oluşturulan öğrenme yaşantıları düzeneğidir (Demirel, 2015). Öğretim programları öğrenciye yönelik kazanımlardan oluşmaktadır. Kazanımlar ise öğretim programlarının belirli bir amaç doğrultusunda planlı bir şekilde yürütülmesini sağlamaktadır. Bu nedenle kazanımlar, programın içeriğinin düzenlenmesi, programın uygulanması ve değerlendirilmesine yardımcı olacak şekilde hazırlanmalıdır (Anderson ve Krathwohl, 2001; Gezer, Şahin, Sünkür ve Meral, 2014). Ayrıca kazanımların, hedeflenen bilgi ve becerileri yansıtır nitelikte olması gerekmektedir (Anderson ve Krathwohl, 2001; Demirel, 2012; Tekin, 2009; Varış, 1996)

Öğretim programı kazanımlarının, uygulayıcılara yarar sağlaması ve kazanımların bilgi/beceri düzeylerinin belirlenmesi amacıyla Bloom (1956) tarafından sınıflandırılması yapılmıştır. Yapılan bu sınıflandırmada öğrencilerin zihinsel öğrenmelerini kolaylaştırmak ve öğrenme düzeylerini arttırmak amaçlanmaktadır (Anderson ve Krathwohl, 2001). Bloom'un orijinal taksonomisinde bilişsel öğrenmeler; bilgi, kavrama, uygulama, analiz, sentez ve değerlendirme adı altında incelenmektedir (Krathwohl, 2002).

Öğrenme - öğretme süreçlerindeki gelişimlerin çağa ayak uydurabilmesi adına orijinal Bloom Taksonomisinde bazı düzenlemelere gitme ihtiyacı doğmuştur. Yenilenmiş taksonomide katı hiyerarşik sıralama esnetilmiş ve kategoriler birbiri ile daha çok bitişik hale getirilmiştir. Ayrıca yenilenmiş Bloom taksonomisindeki terimsel ve yapısal yenilikler öğretimin planlanma sürecini ve hedef yazmayı kolaylaştırmış hem de değerlendirme sürecinde performans değerlendirmeyi etkin kılmıştır (Tutkun, Demirtaş, Arslan, Gür-Erdoğan, 2015).

Bloom'un geliştirmiş olduğu taksonomide, kazanımların tek boyuttan incelenmesinin yetersiz kaldığı ve taksonominin karmaşık bir yapıda olduğu Anderson ve Krathwohl tarafından düşünülmüştür (Tutkun ve Okay, 2012; Zorluoğlu, Kızılaslan ve Sözbilir, 2016). Bu bağlamda kazanımlarla ilgili derinlemesine bilgi edinebilmemiz ve karmaşıklığı en aza indirgeyebilmek amacıyla kazanımları, bilgi ve bilişsel süreç boyutu olmak üzere iki boyuttan aynı zamanda incelenmesinin daha yararlı olacağı düşünülmektedir (Anderson ve Krathwohl, 2001).

Kazanımların iki boyuttan eş zamanlı incelenmesine yardımcı olan tablo taksonomi tablosu olarak adlandırılmaktadır (Tablo 1). Bu iki boyut birbiriyle ilişkili olup öğrenci, bilişsel süreç boyutunun herhangi bir aşamasında bilgi boyutundaki dört çeşit bilgiyi de kullanabilmektedir (Tutkun ve Okay, 2012). Taksonomi tablosunun yatay sütunlarını bilişsel 
süreç boyutu basamakları, dikey sütunlarını ise bilgi boyutu basamakları oluşmaktadır (Krathwohl, 2002). Bu taksonomi boyutlarından yararlanılarak yapılan sınıflandırma, öğreticiler için uygulama aşamasında, program geliştirme uzmanları için ise öğretimin planlanmasında ve değerlendirilmesinde kolaylıklar sağlamaktadır.

\section{YENILENMIŞ BLOOM TAKSONOMISI BOYUTLARI}

\subsection{Bilgi Boyutu}

Bilgi boyutu basamaklarında, uygulayıcılar "Öğrencilere öğretilmesi gerekenler nelerdir?" sorusuna cevap bulabilmektedirler. Yenilenmiş Bloom taksonomisine göre bilgi boyutu basamakları (Anderson, 2005; Ayvacı ve Türkdoğan, 2010; Anderson ve Krathwohl, 2001; Krathwohl, 2002; Köğce, Aydın ve Yıldız, 2009; Wilson, 2014):

1. Olgusal bilgi: Herhangi bir konunun temelini oluşturan bilgileri anlama, kullanma ve ifade etme davranışlarını içerir. Öğrencilerin bilmek zorunda oldukları temel bilgilerdir.

2. Kavramsal bilgi: Bir yapı içinde bulunan kavramlar arasındaki ilişkilerin belirtildiği, kavramların nasıl ilişkilendirildiği ve kavramların bir arada işlevini nasıl gerçekleştirdiğiyle ilgili bilgidir.

3. İşlemsel bilgi: Herhangi bir işlem veya işin nasıl yapılması gerektiği ile ilgili bilgilerdir.

4. Üstbilişsel (farkındalık) bilgi: Biliş ile ilgili bilgidir. Öğrencinin kendi bilişleri ile ilgili bilgiler üzerinde denetim sağlayabildiği bilgilerdir.

\subsection{Bilişsel Süreç Boyutu}

Taksonominin bilişsel süreç boyutu, anlamlı öğrenmeyi amaçlayan yapılandırmacı yaklaşım temel alınarak hazırlanmıştır. Buna göre "Öğrenci derse nasıl aktif katılır?" ve "Öğrenci nasıl anlamlı öğrenir?" sorularına cevap aranarak öğrenilenlerin transferinin arttırılması amaçlanmaktadır.

Yenilenmiş Bloom taksonomisine göre bilişsel süreç boyutu basamakları (Anderson, 2005; Çepni ve Ayvacı, 2006; Krathwohl 2002):

1. Hatırlama: Bilginin uzun süreli bellekten geri getirilmesidir.

2. Anlama: Sözlü veya yazılı eğitim iletilerinin öğrenci tarafından yeniden yapılandırılarak kendi cümleleri ile ifade edilmesidir.

3. Uygulama: Bireyin öğrendiği bilgilerle ilgili problem çözmesi, uygulama ve alıştırma yapması işlemidir.

4. Çözümleme: Parça-bütün ve bütün-parça ilişkisinin nasıl olduğunu belirleme işlemidir.

5. Değerlendirme: Belirli ölçütlere göre yargıya ulaşma işlemidir.

6. Yaratma: Anlamlı ve işlevsel yeni bir ürün oluşturmak amacıyla parçaları birleştirme işlemidir.

\subsection{Taksonomi Tablosu ve Kullanımı}

Taksonomi tablosunu kullanan uygulayıcı, öğretim programlarında belirlenen kazanımları anlayabilecek, öğrenme ile ilgi soruları cevaplayabilecek, öğretimin nasıl yapılması gerektiği hakkında fikir sahibi olacak; öğrendiği varsayılan öğrencilerin nasıl değerlendirilmesi 
gerektiğini belirleyecektir. Bunun sonucunda kazanımların, öğretim etkinlikleri ve değerlendirme ile ne kadar uyumlu olduğu ve öğretim programının ne kadar kullanışlı olduğu hakkında fikir sahibi olacaktır (Anderson ve Krathwohl, 2001; Bümen, 2006; Krathwohl 2002).

Kazanımlar, fiil ifadesi ve ad ifadesi olan cümle yapısından oluşmaktadır. Bu nedenle kazanımın taksonomideki yerinin belirlenmesi için öncelikle kazanım cümlesinin incelenmesi gerekmektedir. Kazanım cümlesinin fiil ifadesi bilişsel süreç boyutu; ad ifadesi bilgi boyutu hakkında bize fikir verecektir. Fakat bazı kazanımların anlaşıır bir dille yazılmaması veya kazanımda birden çok fiil ifadesi ve ad ifadesinin bulunmasından dolayı kazanımların taksonomi tablosuna yerleştirilmesi zorlaşmaktadır (Anderson ve Krathwohl, 2001). Birden fazla fiil ifadesi bulunan kazanımların boyutunun belirlenmesi için üst boyut olan fiil ifadesi seçilmelidir. Kazanım hem hatırlamayı hem de anlamayı ifade eden fiil içeriyorsa bir üst basamak olan anlama basamağı seçilmelidir; kazanım hem olgusal bilgisi hem de kavramsal bilgisi içeriyorsa bu durumda bir üst basamak olan kavramsal bilgi basamağı seçilerek kazanım boyutların kesiştiği yere yerleştirilmelidir (Anderson ve Krathwohl, 2010).

Ders öğretim programı kazanımı, bilgi boyutunun bulunduğu satır ile bilişsel süreç boyutunun bulunduğu sütunun kesişimi olan hücrede gösterilir (Amer, 2006; Anderson, 2005; Bekdemir ve Selim, 2008; Krathwohl 2002; Şahin, 2005). Örneğin, "Maddelerin; tanecikli, boşluklu ve hareketli yapıda olduğunu kavrar." kazanım maddesindeki "Maddelerin; tanecikli, boşluklu ve hareketli yapıda" ad ifadesinde, bazı kavramların terminolojik bilgisi verileceğinden bilgi boyutundaki olgusal bilgiye girdiği düşünülmektedir. "kavrar" fiil ifadesi, bilimsel süreç boyutunda anlama sürecini oluşturan özetleme, tanımlama, açıklama ve yorumlama gibi kavram özellikleri içerdiğinden anlama boyutuna girdiği düşünülmektedir. Elde edilen bilgi boyutu ve bilişsel süreç boyutu taksonomi tablosundaki sütunların kesiştiği hücre olan A2 hücresine yerleştirilir.

Tablo 1.

Yenilenmiş Bloom Taksonomisi Tablosu

\begin{tabular}{lllllll}
$\begin{array}{c}\text { Bilişsel Süreç } \\
\text { Boyutu }\end{array}$ & & & \\
A.Olgusal Bilgisi & & & & & \\
B.Kavramsal Bilgisi & & & & & \\
C.İslemsel Bilgisi & & & & \\
D.Üst bilişsel Bilgi & & & & \\
\hline
\end{tabular}

Çalışmada, Fen Bilimleri Öğretim Programının Bloom'un yenilenmiş taksonomisine uygunluğunu ortaya koymak amaçlanmıştır. Bu bağlamda araştırma kapsamında Fen Bilimleri Öğretim Programı kazanımları yenilenmiş Bloom taksonomisine göre sınıflandırılmıştır. Fen Bilimleri Öğretim Programının yenilenmiş Bloom taksonomisine göre analizi kazanımların hangi bilgi çeşidine ve bilişsel sürece katkı sağladığını ortaya çıkarması açısından oldukça önemlidir. Ayrıca bundan sonra Fen Bilimleri Öğretim Programının değerlendirmesini yapacaklara veri sağlaması, öğretmenler tarafından daha etkili fen öğretiminin gerçekleştirmesi ve öğretim sonunda öğretmenlerin öğretimi etkili bir şekilde değerlendirmeleri açısından da önem taşımaktadır. 
Alanyazında Fen Bilimleri dersi öğretim programının yenilenmiş Bloom taksonomisine göre analizi ile ilgili çalışma bulunmamaktadır (Arseven, Şimşek ve Güden, 2016; Eroğlu ve Kuzu, 2014; Gezer, Şahin, Sünkür ve Öner, 2014; Tanık ve Saraçoğlu, 2011). Bu anlamda yapılan çalışmanın alanyazındaki bu eksikliği gidereceği düşünülmektedir.

Çalışmada "Fen Bilimleri Dersi Öğretim Programı kazanımları yenilenmiş Bloom taksonomisine göre ne düzeydedir?" sorusuna cevap aranmıştır.

Çalışmanın alt problemleri:

1- Fen Bilimleri Dersi Öğretim Programı kazanımları yenilenmiş Bloom taksonomisinin bilgi boyutunda homojen bir dağılım göstermekte midir?

2- Fen Bilimleri Dersi Öğretim Programı kazanımları yenilenmiş Bloom taksonomisinin bilişsel süreç boyutunda homojen bir dağılım göstermekte midir?

\section{YÖNTEM}

Çalışmanın yöntemi doküman incelemesidir. Doküman incelemesinde temel amaç; araştırılması hedeflenen olgu veya olgular hakkında bilgi içeren yazılı materyallerin analiz edilmesidir (Yıldırım ve Şimşek, 2011). Doküman incelemesi özellikle doğrudan görüşme ve gözlem yapmanın mümkün olmadığı durumlarda tek başına bir araştırma yöntemi olarak kullanılmaktadır (Bowen, 2009). Çalışmada 2013 yılında yayınlanan Fen Bilimleri Dersi Öğretim Programı (3-8. sınıflar) kazanımlarının yenilenmiş Bloom taksonomisine göre nasıl bir eğilim gösterdiğini ortaya koymak amacıyla yenilenmiş Bloom taksonomisine göre analizi yapılmıştır. Bu amaçla programda yer alan 330 kazanım incelenmiştir.

Yenilenmiş Bloom taksonomisine göre Fen Bilimleri Dersi Öğretim Programı kazanımlarının incelenmesi üç aşamada gerçekleştirilmiştir. Birinci aşama, yenilenmiş Bloom taksonomisi boyutlarında ortak bir görüş belirleyebilmek amacıyla 6. sınıf "Işık ve Ses" , 7. sınıf "Maddenin Yapısı ve Özellikleri" ve 8. sınıf "Insanda Üreme, Büyüme ve Gelişme" ünite kazanımları yenilenmiş Bloom taksonomisi boyutlarından hangi basamağa gireceği bir kimya eğitimi uzmanı ve iki fen eğitim uzmanı tarafından ortak olarak belirlenmiş ve bu belirleme işlemi sonucunda ortak bir yargıya varılmaya çalışılmıştır. Bu süreçte öncelikle uzman olan araştırmacılar yukarıda belirtilen kazanımların sınıflandırmasını yapabilmek için 'Taksonomi Tablosu ve Kullanımı' bölümünde yer alan bilgiler doğrultusunda kazanımların fiil ifadeleri ve ad ifadelerini belirlemişlerdir. Daha sonra fiil ifadesinin hangi Bilişsel Süreç Boyutuna yerleştirileceği, ad ifadesinin hangi Bilgi Boyutuna yerleştirileceği belirlenmiştir. Belirleme işleminde uzmanlar kazanımın hangi boyuta gireceği ile ilgili düşünceleri sunmuşlar ve bu görüşlerde boyutla ilgili görüş birliği var ise o boyut seçilmiştir. Fakat görüş birliği olmadığı durumlarda, yani üç kişiden en az biri farklı bir boyut belirlediği durumda uzmanlar neden bu boyutu seçtiğini söylemiş ve kazanım üzerinde düşünülerek görüş birliğine varılmaya çalışılmıştır. Görüş birliği sağlanılmadığı durumlarda ise üç uzmandan ikisinin seçtiği boyut kazanımın Bilgi/Bilişsel Süreç Boyutu olarak belirlenmiştir.

İkinci aşamada ise 3-8. sınıfların ünite kazanımları yenilenmiş Bloom taksonomisinde hangi boyutlara yerleşeceği bir kimya eğitim uzmanı ve iki fen eğitim uzmanı tarafından ayrı ayrı belirlenmiştir. Son aşamada ise yapılan çözümlemeler üç uzmanın bir araya gelmesi ile her bir kazanımın analizinin kontrolü sağlanmıştır. Bu sayede araştırmacılar arası görüş birliği ve ayrılığı tespit edilmiştir. Buna bağlı olarak Miles ve Huberman (1994)'ün belirlemiş olduğu "Görüş Birliği/ (Görüş Birliği + Görüş Ayrılığı)" güvenirlik katsayısı formülü "görüş birliğine varılan kazanım sayısı/ toplam kazanım sayısı" şeklinde revize edilerek çalışmanın güvenirlik hesaplaması yapılmış ve güvenirlik katsayısı .88 bulunduğundan kazanımların analizinin güvenilir olduğu düşünülmektedir. 


\subsection{Verilerin Analizi}

Çalışmada kazanımların taksonomi tablosundaki yerini belirlemek amacı ile araştırmacılar tarafından her bir kazanımın ad ve fiil ifadeleri belirlenerek (Krathwohl 2002), kazanımların bilgi boyutu ve bilişsel süreç boyutunda hangi basamağa girdiği tespit edilmiştir. Daha sonra kazanımın Taksonomi tablosundaki yeri belirlenmiştir. Örnek kazanım analizi: 3.1.1.1. "Duyu organlarını tanır." kazanımının taksonomi tablosunda hangi hücreye girdiğini belirlemek amacı ile "Duyu organlarını" ad ifadesi ve "tanır" fiil ifadesine ayrılmıştır. Ad ifadesi temel kavramlar içerdiğinden olgusal bilgide yer almakta iken fiil ifadesi hatırlama düzeyinde olduğundan A1 hücresine yerleştirilmiştir.

Yapılan bu analize benzer olarak çalışmada yer alan analiz düzeyleriyle ilişkili kazanım analiz örnekleri verilecektir: 6.3.1.1 "Maddelerin; tanecikli, boşluklu ve hareketli yapıda olduğunu kavrar." kazanımında "Maddelerin; tanecikli, boşluklu ve hareketli yapıda" ad ifadesi olgusal bilgi düzeyindedir. "kavrar" fiil ifadesi anlama düzeyinde olduğundan dolayı ilgili kazanım A2 hücresine yerleştirilmiştir. 5.4.2.1 "Maddeleri, ışığı geçirme durumlarına göre sınıflandırır ve örnekler verir." kazanımında ise "Maddeleri, ışı̆̆ı geçirme durumları" ad ifadesi kavramsal bilgi iken "sınıflandırır ve örnekler verir" fiil ifadesi hatırlama düzeyindedir. Bu nedenle kazanım B1 hücresine yerleştirilmiştir. 4.4.5.2 "Ses kirliliğinin insan sağlığı ve çevre üzerindeki olumsuz etkilerini açıklar." kazanımının ad ifadesi "Ses kirliliğinin insan sağlığı ve çevre üzerindeki olumsuz etkilerini" kavramsal bilgi iken fiil ifadesi "açıklar" anlama düzeyinde olduğundan B2 hücresine yerleştirilmiştir. 7.1.3.2 "iç salgı bezlerinin vücuttaki yerlerini model üzerinde gösterir ve görevlerini açıklar." kazanımında ise "iç salgı bezlerinin vücuttaki yerlerini" ad ifadesi kavramsal bilgi düzeyinde iken "model üzerinde gösterir ve görevlerini açıklar" fiil ifadesi uygulama düzeyinde olduğundan B3 hücresine yerleştirilmiştir. 7.7.1.3 "Yıldızlar ile gezegenleri karşılaştıırı." kazanımda "Yıldızlar ile gezegenleri" ad ifadesi kavramsal bilgi düzeyinde yer almakta iken "karşılaştııı" fiil ifadesi çözümleme basamağında yer aldığından kazanım B4 hücresinde yer almaktadır. 7.2.4.1 "Kinetik ve potansiyel enerji türlerinin birbirine dönüştüğünü örneklerle açıklar ve enerjinin korunduğu sonucunu çıkarır." kazanımının ad ifadesi kavramsal bilgi iken fiil ifadesi değerlendirme düzeyinde olduğundan B5 hücresine yerleştirilmiştir.

8.3.6.3 "Kimya endüstrisinde meslek dallarını araştırır ve gelecekteki yeni meslek alanlarının neler olabileceği hakkında tahminlerde bulunur." kazanımının "Kimya endüstrisinde meslek dallarını ..... ve gelecekteki yeni meslek alanlarının neler olabileceği" isim ifade bilimsel süreç becerileri gerektiğinden işlemsel bilgi düzeyinde, "araştırır ...... tahminlerde bulunur" fiil ifadesi ise uygulama ve anlama düzeyindedir. Fakat bir üst bilişsel süreç becerisi belirlenmesi gerektiğinden uygulama düzeyi belirlenmiş ve kazanım C3 hücresine yerleştirilmiştir. 7.6.1.2 "Ampullerin seri ve paralel bağlandığı durumlardaki parlaklık farklııklarını devre üzerinde gözlemler ve sonucu yorumlar." kazanımının ad ifadesi "Ampullerin seri ve paralel bağlandığı durumlardaki parlaklık farklılıklarını" işlemsel bilgi düzeyinde, "devre üzerinde gözlemler ve sonucu yorumlar." fiil ifadesi ise uygulama ve çözümleme düzeyindedir. Fakat daha detaylı olan bir üst basamağın seçilmesi gerektiğinden çözümleme düzeyi olduğu belirlenmiş ve C4 hücresine yerleştirilmiştir.

4.1.4.3 "Egzersiz yapmanın vücut sağlığı açısından önemini fark eder." kazanımının "egzersiz yapmanın vücut sağlığı açısından önemini" ad ifadesi farkındalık gerektiğinden üst bilişsel bilgi düzeyindedir. "fark eder" fiil ifadesi anlama düzeyine girdiğinden kazanım D2 hücresine yerleştirilmiştir. 7.3.5.4 "Yakın çevresinde atık kontrolü sorumluluğunu geliştirir." kazanımının "Yakın çevresinde atık kontrolü sorumluluğunu" ad ifadesi farkındalık gerektirdiğinden üst bilişsel bilgi düzeyinde, "geliştirir" fiil ifadesi ise yaratma düzeyinde olduğundan D6 düzeyine yerleştirilmiştir. 


\section{BULGULAR}

Bu çalışmada, Fen Bilimleri Öğretim Programında yer alan 330 kazanım yenilenmiş Bloom taksonomisine göre incelenerek, kazanımların taksonomisindeki yeri belirlenmiştir. Buna göre yenilenmiş Bloom taksonomisinde yer alan boyutlar ve alt boyutlara göre dağılımın nasıl gerçekleştiğinin daha iyi görülmesi amacıyla farklı grafikler sunulmuştur.

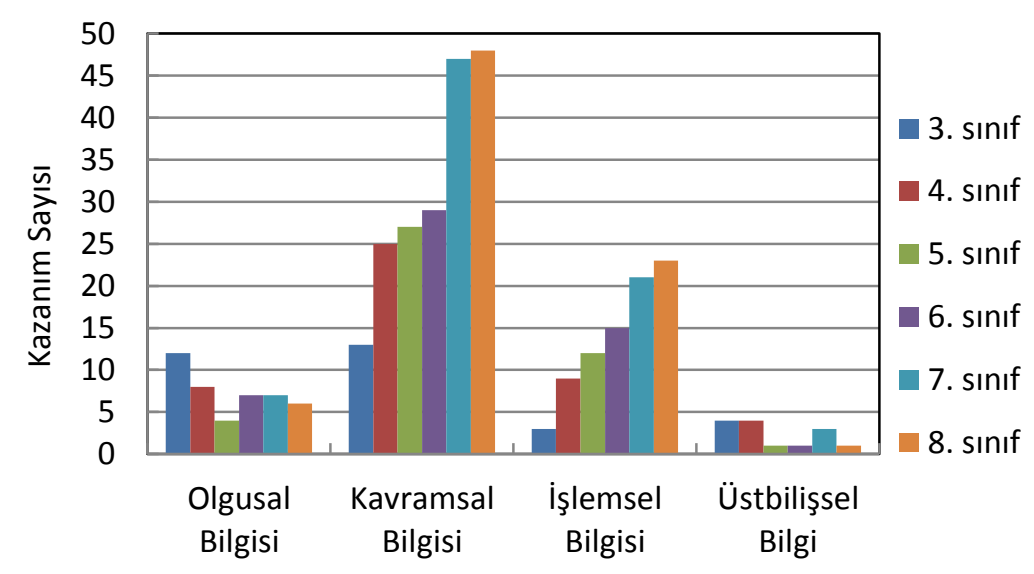

Şekil 1. Fen Bilimleri Dersi Öğretim Programı kazanımlarının bilgi boyutu alt basamaklarına göre dağılımı

Şekil 1'de yenilenmiş Bloom taksonomisi bilgi boyutu alt basamaklarına göre Fen Bilimleri Dersi Öğretim Programında yer alan kazanımların analizi yapılmıştır. Fen Bilimleri Dersi Öğretim Programında en az üst bilişsel bilgiye yönelik kazanımlara yer verildiği belirlenmiştir (Şekil 1). En çok yer verilen bilgi türü ise kavramsal bilgidir. Genel olarak Şekil 1'e bakıldığında kazanımların bilgi boyutlarına homojen olarak dağılmadığı görülmektedir. Şekil 2 ise bu durumunu oransal olarak desteklemektedir. Ayrıca Şekil 1'deki gibi olgusal bilgi düzeyindeki kazanımların üst sınıflara geçildikçe sayısının azalması ve işlemsel bilgi düzeyindeki, kazanım sayısında artışın olması (Anderson ve Krathwohl, 2001) gerekmektedir.

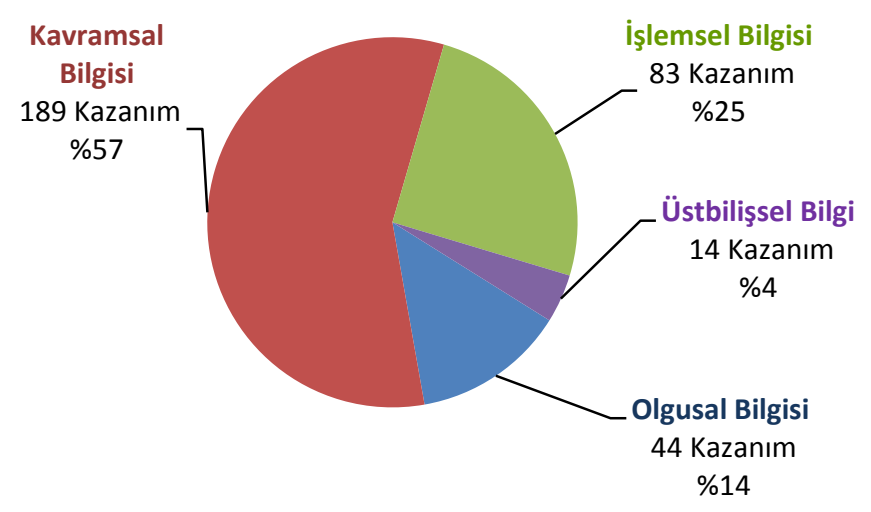

Şekil 2. Fen Bilimleri Dersi Öğretim Programı kazanımlarııın bilgi boyutu alt basamaklarının yüzde dağııımı

Şekil 2'ye göre kazanımların \%57'si kavramsal bilgisi (189 kazanım), \%25'i işlemsel bilgisi ( 83 kazanım), \%14'ü olgusal bilgi (44 kazanım) ve \%4'ü üst bilişsel bilgi (14 kazanım) düzeyindedir. 


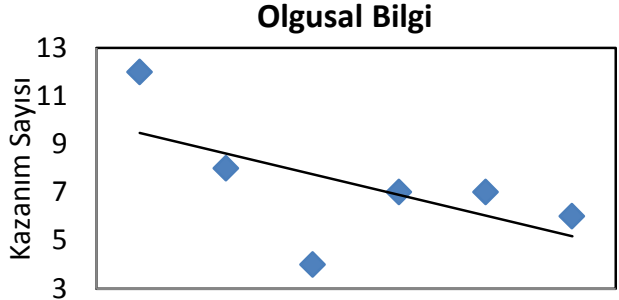

3. $\sin ı f 4 . \sin ı f 5 . \sin i f 6 . \sin 1 f 7 . \sin 1 f 8 . \sin ı f$

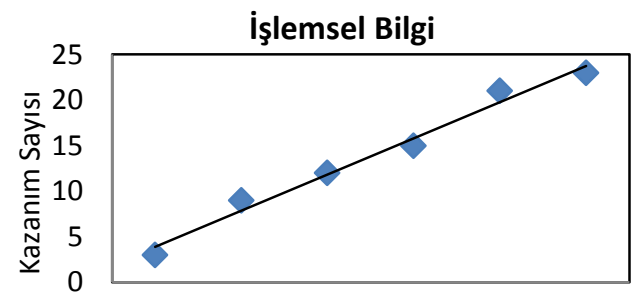

3. sınıf 4. sınıf5. sinıf6. sınıf7. sınıf 8. sinıf

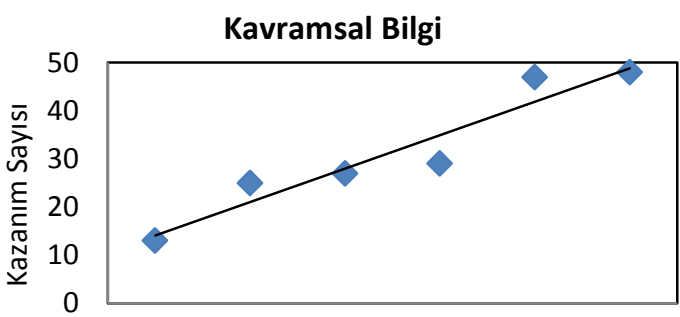

3. sınıf 4. sınıf 5. sinıf 6. sinıf 7. sinıf 8. sinıf

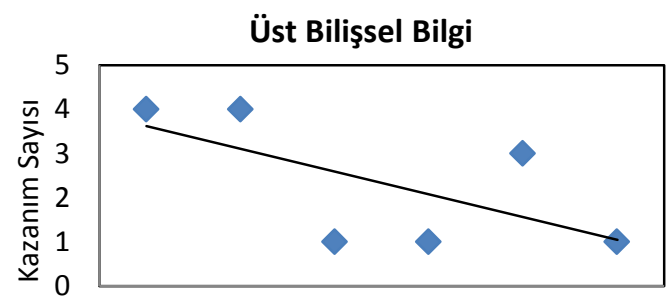

3. sınıf 4. sinıf 5. sinıf 6. sinıf 7. sinıf 8. sinıf

Şekil 3. Kazanımların bilgi boyutlarına ve sınıflara göre dağılımı

Kazanımların her bir bilgi boyutundaki dağılımları sınıf düzeylerine göre incelendiğinde Şekil 3 elde edilmiştir. Şekil 3'e bakıldığında kavramsal ve işlemsel bilgi düzeyindeki kazanımlar pozitif eğilim göstererek üst sınıflara geçildikçe ilgili kazanım sayısı artmaktadır. Olgusal ve üst bilişsel bilgi düzeyindeki kazanımların sayısında ise üst sınıflara geçildikçe azalma olduğundan negatif eğilim göstermiştir. Hâlbuki üst sınıflara geçildikçe kazanımların büyük bir bölümünün üst bilişsel bilgi düzeyinde ya da üst bilişsel bilgi düzeyine yakın bilgi boyutlarından olması (Anderson ve Krathwohl, 2001) ve olgusal bilgi ile ilgili kazanımların sayısının azalması gerekmektedir. Şekil 3'te bulunan grafikler üst bilişsel bilgi düzeyi ile ilgili bu durumu geçerli kılmazken olgusal bilgi düzeyi ile ilgili durumu geçerli kılmaktadır.

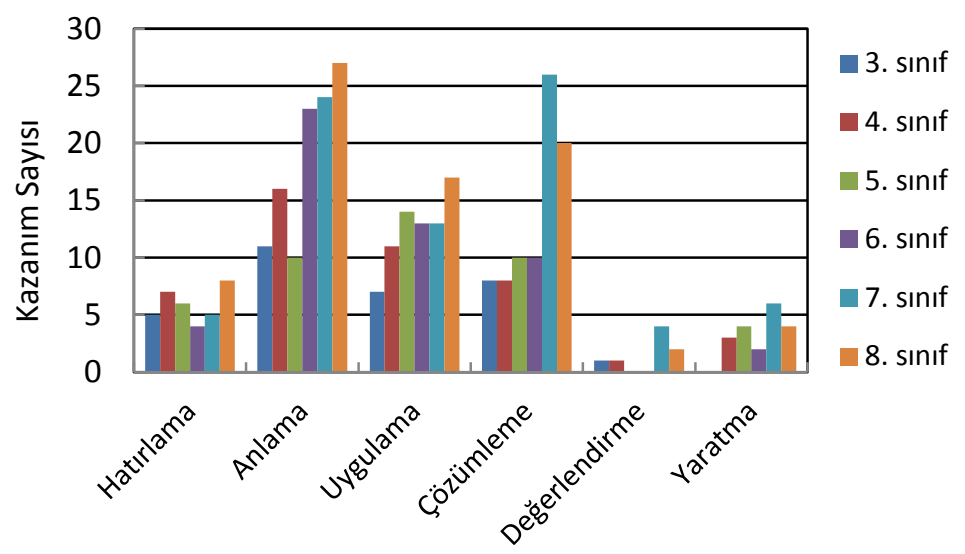

Şekil 4. Fen Bilimleri Dersi Öğretim Programı kazanımlarının bilişsel süreç boyutu alt basamaklarına göre dağılımı

Fen Bilimleri Dersi Öğretim Programında yer alan kazanımların yenilenmiş Bloom taksonomisi bilişsel süreç boyutu basamaklarına göre analiz grafikleri Şekil 4'te verilmiştir. Buna göre programda anlama düzeyindeki kazanımlara ağırlık verildiği anlaşılmaktadır. Şekil 4 genel olarak değerlendirildiğinde değerlendirme ve yaratma düzeylerinde daha az kazanıma ver verildiği görülmektedir. 


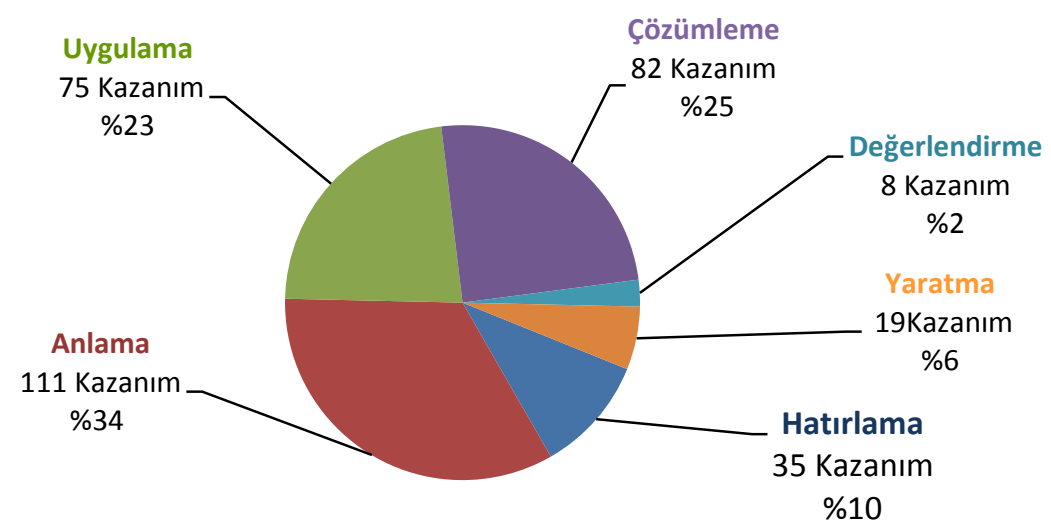

Şekil 5. Fen Bilimleri Dersi Öğretim Programı Kazanımlarının bilişsel süreç boyutu alt basamaklarıın yüzde dağııımı

Fen Bilimleri Dersi Öğretim Programı kazanımlarının \%34'ü anlama (111 kazanım), \%25'i çözümleme (82 kazanım), \%23'ü uygulama (75 kazanım), \%10'u hatırlama (35 kazanım), $\% 6$ 'sı yaratma (19 kazanım) ve \%2'si değerlendirme (8 kazanım) düzeyindedir (Şekil 5). Analiz sonuçlarına göre program kazanımlarının $\% 90$ 'ını anlama ve üstü düzeydeki kazanımlar oluşturmaktadır.

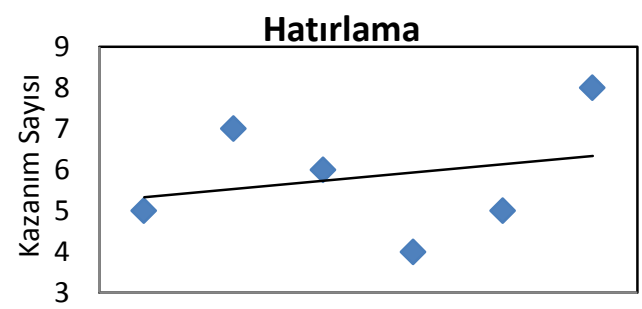

3. sınıf 4. sinıf 5. $\sin ı f 6 . \sin ı f 7 . \sin$ If 8. sinıf

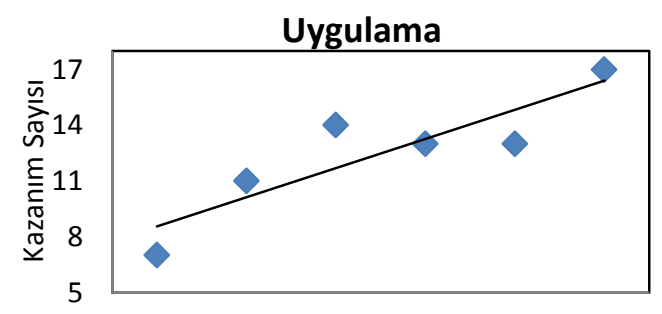

3. sinıf 4. sinıf 5. sinıf 6. sinıf 7. sinıf 8. sinıf

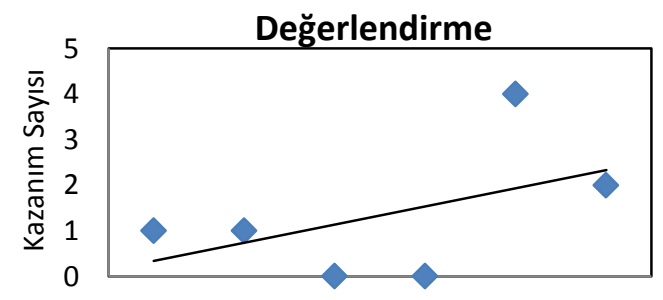

3. sinıf 4. sinıf 5. sinıf 6. sinıf 7. sinıf 8. sinıf

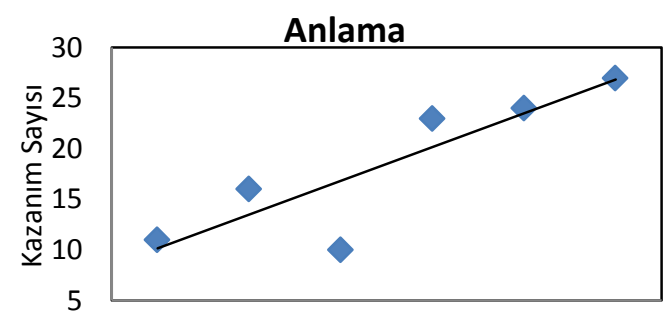

3. $\sin$ If 4. sinıf 5. $\sin$ If 6. sinıf 7. sinıf 8. sinıf

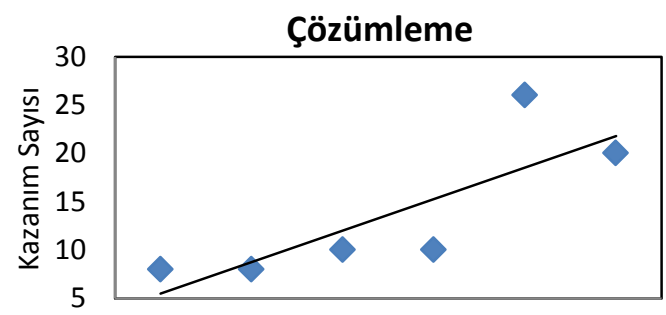

3. sınıf 4. sinıf 5. sinıf 6. sınıf 7. sinıf 8. sinıf

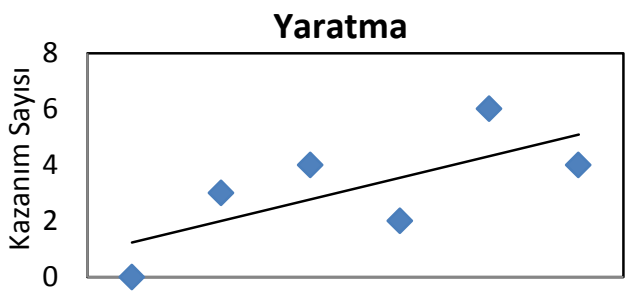

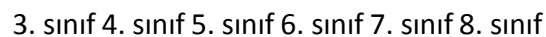

Şekil 6. Kazanımların Bilişsel Süreç Boyutlarına ve Sınıflara Göre Dağııımı

Şekil 6'da her bir bilişsel süreç boyut basamaklarında eğimin pozitif olduğu görülmektedir. Fakat hatırlama düzeyindeki kazanımların üst sınıflara gidildikçe etkisini 
yitirmekte olduğu (Anderson ve Krathwohl, 2001), anlama düzeyindeki kazanımların ise üst sınıflara doğru etkisini yitirmesi gerekirken daha fazla ağırlık verildiği görülmektedir. Uygulama, çözümleme, değerlendirme ve yaratma düzeyindeki kazanımların son sınıflara doğru gidildikçe sınıf düzeylerine göre etkisinin artması beklenir. Şekil 6 bu basamakların her ne kadar etkisinin arttı̆̆ını gösterse de Şekil 4 bu basamaklarla ilgili kazanımların yetersiz olduğunu göstermektedir.

Tablo 2.

Kazanımların Yenilenmiş Bloom Taksonomisine Göre Dağııımı

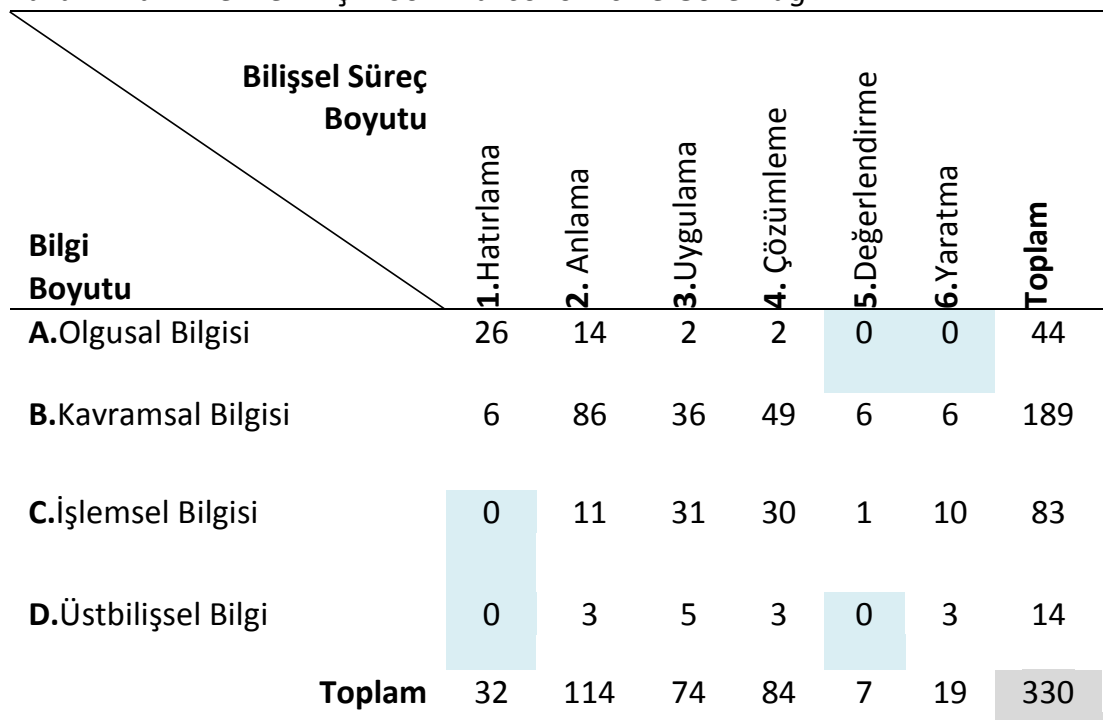

Fen Bilimleri Dersi Öğretim Programında yer alan 330 kazanımın yenilenmiş Bloom taksonomisine göre analiz sonuçları taksonomi tablosuna (Tablo 2) yerleştirilmiştir. Tablo 2, Fen Bilimleri Dersi Öğretim Programı kazanımlarının genel eğilimi hakkında bilgi vermektedir. Tablo 2 ve Şekil 1-6 öğretmenlere, öğrencilere öğretilecek konuların bilgi ve bilişsel süreç boyutlarının alt boyutlarından en az hangisine göre dersin işlenmesi gerektiği hakkında bilgi verecektir.

\section{SONUÇ, TARTIŞMA VE ÖNERILER}

Yapılan analizin sonuçlarına göre Fen Bilimleri Öğretim Programında, bilgi boyutu basamaklarından daha çok kavramsal bilgiye yönelik kazanımlar yer alırken en az üst bilişsel bilgiye yer verilmiştir (Şekil 2).

Programın bilişsel süreç boyutuna göre analizinde, en çok anlama basamağı düzeyinde, en az ise değerlendirme düzeyinde kazanımlara yer verildiği belirlenmiştir (Şekil 5). Anderson ve Krathwohl (2001), genellikle bir programda yer alan kazanımların bilişsel süreç boyutu basamaklarından hatırlama, anlama ve uygulamaya basamaklarına daha çok yer verildiğini, çözümleme, değerlendirme ve yaratma basamaklarına ise çok az yer verildiğini belirtmektedirler. Etkili bir öğretim programı için kazanımlar en az anlama düzeyinde olmalıdır (Anderson ve Krathwohl, 2001). Bu durum programda yer alan kazanımların daha çok anlama düzeyinde olması gerektiği anlamına gelmemektedir. Bu bağlamda Fen Bilimleri Öğretim Programı kazanımlarının anlama düzeyi ağırlıklı hazırlandığı ve üst düzey bilişsel süreç boyutlarına ise yeteri kadar yer verilmediği ortaya çıkmıştır.

Mayer (2002), öğrenilen bilgilerin transferi için uygulama, çözümleme, değerlendirme ve yaratma basamaklarıyla ilgili öğretim kazanımlarına yer verilerek anlamlı öğrenmenin gerçekleşebileceğini söylemektedir. Şekil 4-5 incelendiğinde mevcut programdaki, Mayer (2002)'in belirtmiş olduğu bilişsel süreç becerileriyle ilgili kazanımlar genel kazanımların 
\%56'sını oluşturmaktadır. Bu durum Fen Bilimleri Öğretim Programının anlamlı öğrenmede yeterli olduğunu göstermektedir. Fakat program analizlerinde genel durumu sağlıklı değerlendirmek amacı ile sınıf düzeyleri veya ünite düzeylerine bakmak gerekmektedir (Anderson ve Krathwohl, 2010). Tablo 4 ve Tablo 6 sınıf düzeylerine göre ayrı ayrı incelendiğinde uygulama, çözümleme, değerlendirme ve yaratma basamaklarının her biri ile ilgili kazanımlara anlama basamağından daha az yer verildiği görülmektedir. Bu durum sınıf düzeyi olarak programın anlamlı öğrenme sağlamada yetersiz kalacağını düşündürmektedir.

Öğrencilerin üst düzey bilişsel becerileri kazanması için üst düzey bilişsel boyutlara yönelik kazanımların ve etkinliklerin sunulması gerekmektedir (Aydın ve Yılmaz 2010; Senemoğlu, 2001; Zorluoğlu, Kızılaslan ve Sözbilir, 2016). Yapılan çalışmada öğrenci öğrenmelerini arttıracak üst düzey bilişsel süreçler yer almakta olduğu fakat daha çok çözümleme basamağına yer verildiği, değerlendirme ve yaratma basamağına daha az yer verildiği belirlenmiştir (Şekil 5). Bu durum ise öğrencinin yaratıcılığını ve çıkarım yapmasını arttıracak kazanımlara programda yeteri kadar yer verilmediğini göstermektedir.

Sınıf düzeyinde incelenen kazanımların bilişsel süreç boyutunun üst basamaklarına yönelik kazanımların son sınıfa doğru arttığı (Şekil 3 ve Şekil 6), fakat Şekil 4 incelendiğinde son sınıfa doğru gidildikçe bilişsel süreç boyutun son basamaklarına yönelik kazanımlardan daha çok anlama basamağına yönelik kazanımların olduğu anlaşılmaktadır. Ayrıca bilgi boyutunun üst basamaklarından işlemsel bilgiye yönelik kazanımlar üst sınıflara doğru artış gösterirken üst bilişsel bilgiye yönelik kazanımların sayısı azalmaktadır. Sınıf düzeyleri bakımından ilk sınıflarda boyutun ilk basamaklarının, son sınılara doğru ise son basamaklardaki boyutlarının ön plana çıkması gerekmektedir (Anderson ve Krathwohl, 2001). Bu sonuç, program yapılırken Anderson ve Krathwohl'un bu düşüncesine dikkate edilmediğini ya da konu içeriklerini yönlendirecek kazanımların bu duruma uygun olmadığını düşündürmektedir.

Etkili öğrenme için kazanımların, bilgi boyutu basamaklarında konu alanları ve sınıf düzeyleri için farklılık göstermesi gerekmektedir (Anderson ve Krathwohl, 2001). Çalışmaya genel olarak bakıldığında program kazanımlarının farklı bilgi boyutu basamaklarına dağıldığı, bu nedenle programın etkili öğrenmeyi destekleyecek nitelikte olduğu görülmektedir.

Öğrenciler öğrenim sürecinde, bilişsel seviyesi düşük kazanımlar ve sorularla karşılaşması halinde basit düzeyde düşünmeye; bilişsel seviyesi yüksek kazanımlar ve sorularla karşılaştıklarında ise daha fazla zihinsel faaliyet sergilemeye yöneltir ki, bu durum öğrencileri daha yaratıcı ve sorgulayıcı olmaya zorlamaktadır (Çepni, Ayvacı ve Keleş, 2001). Bu yüzden Fen Bilimleri Dersi Öğretim programının revize edilmesi durumunda, öğrencilerin daha fazla zihinsel faaliyetlerde bulunmalarını sağlamak amacı ile Eroğlu ve Kuzu (2014)'ünde çalışmalarında belirttiği gibi üst düzey bilgi ve bilişsel süreç boyutu basamaklarına ağırlık verilmesi öğrenmeleri aktif kılacaktır.

Öğretimin amacı, öğrenilenlerin transferini arttırmaktır. Transferin arttırılması hatırlama ve anlama basamağından çok yaratma basamağına kadar uzanmaktadır. Öğretim programları genellikle anlama düzeyinde hazırlandığından bilgi transferinde yetersiz kalmaktadır (Anderson ve Krathwohl, 2001). Aynı durum Fen Bilimleri Dersi Öğretim Programının kazanımları için de geçerlidir. Bilgi transferlerini arttırmak ve aktif düşünen, öğrendiğini kullanan ve yeni bilgiler üreten bireylerin yetişmesine katkı sağlamak amacı ile Fen Bilimleri Öğretim Programı hazırlanırken son sınıflara doğru üst bilişsel süreç basamaklarını içeren kazanımlara yer verilmesi gerekmektedir. Ayrıca SOLO, Fink ve Dettmer gibi farklı bilişsel alan taksonomilerine göre fen öğretim programı incelenerek farklı bakış açıları edinilebilir.

Daha sonraki çalışmalarda ilköğretim ve Ortaöğretim Kurumlarındaki farklı derslerin öğretim programları da yenilenmiş Bloom taksonomisine göre incelenerek genel bir durum 
ortaya konulabilir. Ayrıca Türkiye'deki Fen Öğretim Programının Dünyadaki yerini görebilmek amacıyla farklı ülkelerin de fen öğretim programları yenilenmiş Bloom taksonomisine göre karşılaştırmalı olarak incelenebilir.

\section{KAYNAKLAR}

Amer, A. (2006). Reflections of Bloom's revised taxonomy. Electronic Journal of Research in Educational Psychology, 4(8), 213-230.

Anderson, L. W. \& Krathwohl, D.R. (Eds.). (2001). Taxonomy for learning, teaching and assessing: A revision of Bloom's taxonomy of educational objectives. Needham Heights, MA: Allyn \& Bacon.

Anderson, L.W., \& Krathwohl, D.R. (2010). (Çeviren: D.A. Özçelik). Öğrenme öğretim ve değerlendirme ile ilgili bir sınıflama (Kısaltılmış basım). Ankara: Pegem Akademi.

Anderson, L. W. (2005). Objectives, evaluation, and the improvement of education. Studies in Education Evaluation, 31, 102-113.

Arseven, A., Şimşek, U., \& Güden, M. (2016). Coğrafya dersi yazılı sınav sorularının yenilenmiş Bloom taksonomisi'ne göre analizi. Cumhuriyet Üniversitesi Edebiyat Fakültesi Sosyal Bilimler Dergisi, 40(1), 243-258.

Aydın, N., Yılmaz, A. (2010). Yapılandıııcı yaklaşımın öğrencilerin üst düzey bilişsel becerilerine etkisi. Hacettepe Üniversitesi Eğitim Fakültesi Dergisi, 39, 57-68.

Bloom, B. S. (1956). Taxonomy of educational objectives, the classification of educational goals, handbook I: Cognitive domain. New York: David McKay Company.

Bekdemir, M., Selim, Y. (2008). Revize edilmiş Bloom taksonomisi ve cebir öğrenme alanı örneğinde uygulaması. Erzincan Eğitim Fakültesi Dergisi,10(2), 185-196.

Bowen, A. G. (2009). Document analysis as a qualitative research method. Qualitative Research Journal, 9(2), 27-40.

Bümen, T. N. (2006). Program geliştirmede bir dönüm noktası: Yenilenmiş Bloom taksonomisi. Eğitim ve Bilim, 31 (142), 3-14.

Çepni, S. (2006). Bilim, fen, teknoloji kavramlarının eğitim programlarına yansımaları. S. Çepni (Ed.), kuramdan uygulamaya fen ve teknoloji öğretimi içinde (ss.2-22). Ankara: Pegem Yayıncilık.

Çepni, S., \& Ayvacı, H. Ş. (2006). Fen ve teknoloji eğitiminde ölçme ve değerlendirme. S. Çepni (Ed.), kuramdan uygulamaya fen ve teknoloji öğretimi içinde (ss.229-248). Ankara: Pegem Yayıncılık.

Demirel, Ö. (2012). Kuramdan uygulamaya eğitimde program geliştirme. Ankara: Pegem Yayıncilık.

Demirel, Ö. (2011). Öğretim ilke ve yöntemleri öğretme sanatı. Ankara: Pegem Yayıncılık.

Eroğlu, D., \& Kuzu, T. S. (2014). Türkçe ders kitaplarındaki dilbilgisi kazanımlarının ve sorularının yenilenmiş Bloom taksonomisine göre değerlendirilmesi. Başkent University Journal of Education, 1(1), 72-80.

Gezer, M., Şahin, i. F., Sünkür, M. Ö., Meral, E. (2014). 8. Sınıf Türkiye Cumhuriyeti İnkılâp Tarihi Ve Atatürkçülük dersi öğretim programı kazanımlarının revize edilmiş Bloom taksonomisine göre değerlendirilmesi. Bartın Üniversitesi Eğitim Fakültesi Dergisi, 3(1), 433-455. 
Küçükahmet, L. (2009).Program geliştirme ve öğretim. Ankara: Nobel Yayıncılık.

Mayer, R.E. (2002). Rote versus meaningful learning. Theory Into Practice, 41(4), 226-232.

Miles, M. B. \& . Huberman A.M (1994). Qualitative data analysis: An expanded sourcebook. (2nd Edition). California: Sage Publications

Milli Eğitim Bakanlığı (2006). Fen ve teknoloji öğretim programı. Ankara: Talim ve Terbiye Kurulu Başkanlığı.

Senemoğlu, N. (2001). Gelişim öğrenme ve öğretim. Ankara: Gazi Kitapevi

Tanık, N., \& Saraçoğlu, S. (2011). Fen ve teknoloji dersi yazılı sorularının yenilenmiş Bloom taksonomisine göre incelenmesi. TÜBAV Bilim Dergisi, 4(4), 235-246.

Tutkun, Ö. F., \& Okay, S. (2012). Bloom'un yenilenmiş taksonomisi üzerine genel bir bakış. Sakarya University Journal of Education, 1(3), 14-22.

Tutkun, Ö.F., Demirtaş, Z., Arslan, S., Gür-Erdoğan, D. (2015). Revize Bloom taksonomisinin genel yapısı: Gerekçeler ve değişiklikler. The Journal of Academic Social Science Studies, 32(3), 57-62.

Uslu, S., \& Akgün, A. (2016). İlköğretim II. kademede fen ve teknoloji öğretiminde çalışma yapraklarının akademik başarı üzerine etkisinin incelenmesi. Bayburt Eğitim Fakültesi Dergisi, 7(2), 157-168.

Wilson, L. O. (2014), “Anderson and Krathwohl-Bloom's Taxonomy Revised: Understanding the New Version of Bloom's Taxonomy", Erişim tarihi: 13 Mayıs 2015, http://thesecondprinciple.com/teaching-essentials/beyond-bloom-cognitive-taxonomyrevised/.

Yıldırım, A. \& Şimşek, H. (2011). Sosyal bilimlerde nitel araştırma yöntemleri (8.baskı). Ankara: Seçkin Yayıncılık.

Zorluoğlu, S. L., Kızılaslan, A. \& Sözbilir, M. (2016). Ortaöğretim kimya dersi öğretim programı kazanımlarının yapılandırılmış Bloom taksonomisine göre analizi ve değerlendirilmesi. Necetibey Eğitim Fakültesi Elektronik Fen ve Matematik Eğitimi Dergisi, 10 (1), 260-279. 


\section{SUMMARY}

Learning outcomes in science teaching curriculum aim to help students learn by experiency and gain necessary attitudes and skills based on their talents (Çepni, 2006; Uslu ve Akgün, 2016).

Science curriculum is composed of learning outcomes. Learning outcomes are prepared to help organisation, administration and evaluation of learning content (Anderson ve Krathwohl, 2001; Gezer, Şahin, Sünkür ve Meral, 2014). Therefore, learning outcomes are investigated considering two dimensions to reduce misunderstandings about them, and have knowledge in depth.

In the revised taxonomy, knowledge is based on of these four cognitive processes: factual knowledge, conceptual knowledge, procedural knowledge and metacognitive knowledge. To remember, understand, apply, analyze and evaluate is included in the cognitive process domain categories.

In this study, it is aimed to find out the learning outcomes in science course curriculum that was initiated to apply in 2013, focusing on level and tendency according to revised Bloom Taxonomy. For this purpose, the learning outcomes in science course curriculum have been examined and classified on the basis of Revised Bloom Taxonomy. This study aimed to find out an answer to the question "What are the learning outcomes of science curriculum as compared to the resived Bloom Taxonomy?”

Sub-problems of the study:

1. To what extent do learning outcomes of science teaching curriculum have homogen distribution at the stage of knowledge of revised Bloom Taxonomy?

2. To what extent do learning outcomes of science teaching curriculum have homogen distribution in the dimension of cognitive process of the revised Bloom Taxonomy?

This is a document analysis study. Document analysis reviews paper or electronic documents or it is used to evaluate (Bowen, 2009). Document analysis can be used as any of qualitative methods as a complement or an independent method (Bowen, 2009). In this study, the analysis of the 330 learning outcomes of science course curriculum published is performed. This analysis of the outcomes is performed in three stages.

In the first stage, to be able to reach a joint judgement on the dimensions of the revised Bloom Taxonomy, a chemistry education specialist and two science education specialists examined the learning outcomes of the units of 'light and sound' for grade 6, 'structure and properties of substance' for grade 7, and 'human fertility, growth and development' for grade 8 and tried to placed them on the dimensions of the revised Bloom Taxonomy. In the learning outcomes targeted were shared by researchers taking the joint judgement reached during the first stage into consideration. In the last stage, randomly selected samples of the analysis were checked and consensus and divergence among researchers' analyses were determined to assign the reliability of the study. The reliability coefficient was calculated as .88. The analysis is expected to be reliable because it is greater than .70 .

Researchers investigated the learning outcomes by determining actions of them and it was determined that which stage of the learning outcomes fall into at the dimensions of knowledge and cognitive process (Krathwohl, 2002), then place of the learning outcome was found from the Taxonomy. Example analysis of learning outcomes: 3.1.1.1 'to know sense organs'. This learning outcome was divided into 'sense organs' as object and "know" as verb. The statement of verb was inserted into A1 cell, while the statement of object is at the phenomenological knowledge due to the fact that it includes basic concepts.

The analysis results showed distribution of the learning outcomes in the knowledge domain are metacognitive (\%4), factual (\%14), procedural (\%25) and conceptual (\%57). The distribution of learning outcomes in cognitive process domain are evaluate $(\% 2)$, create $(\% 6)$, remember $(\% 10)$, apply (\%23), analyze (\%25) and understand (\%34).

According to the analysis results it has been defined that in the knowledge dimension: the most learning outcomes are given in the conceptual knowledge, at least learning outcomes are given in the metacognitive knowledge; in cognitive processes dimension the most learning outcomes are given at the level of understand, at least learning outcomes are given at the level of the evaluation stage. It has 
been found out that the senior metacognitive process dimensions have not been taking place adequately in the learning outcomes of science course curriculum. Furthermore, it has been induced that there has not been a homogenous distribution of the learning outcomes at the metacognitive dimension step and there has not been a focus on the learning outcomes that are related to the senior cognitive dimension, and activating a learnings of students. 